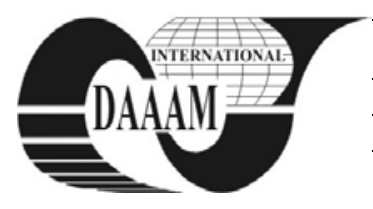

Annals of DAAAM for 2011 \& Proceedings of the 22nd International DAAAM Symposium, Volume 22, No. 1, ISSN $1726-9679$ ISBN 978-3-901509-83-4, Editor B. Katalinic, Published by DAAAM International, Vienna, Austria, EU, 2011 Make Harmony between Technology and Nature, and Your Mind will Fly Free as a Bird Annals \& Proceedings of DAAAM International 2011

\title{
A DESIGN FOR A NETWORK END NODE, BASED ON ARDUINO AND XBEE
}

\author{
BUJDEI, C[atalin] \& MORARU, S[orin] - A[urel]
}

\begin{abstract}
We needed a design for a network end node which to be used for implementing a wireless sensors network, with the role of making intelligent an office building. The automation process supposes to monitor different ambient parameters values and also to control the existent systems (e.g. airconditioning, heating, ventilation). This paper presents the research work done for determining the best suitable node design necessary for our purpose, the node device developed as a result of this research, the tests accomplished with it and possibilities of optimization. The main characteristics of the proposed node design are: easily implementable at a low cost, modular, could be easily adapted for different types of applications and it has a small physical size.

Key words: wireless sensors network, network node design, Arduino, XBee, building automation
\end{abstract}

\section{INTRODUCTION}

In the last years the wireless sensors networks (WSN) domain knew a wide development. The technology has been perfected, in a try to avoid the main existent problems or constraints. The wireless communication has multiple advantages compared to the wired communication, but also disadvantages. Even the technology evolved, the implementation of this type of networks in real life is limited, limitation determined especially because of the high cost of the network devices (nodes) or, for some types of nodes, because they could not be adapted to specific types of applications. It is important to consider, at the design stage of a device, the general aspect of it (do not limit its features only for one application).

Into a wireless sensors network, there could be 3 logical types of network devices (nodes): coordinator (one and only one could exist into a network; it initializes the network), router (there could be many nodes of this type into a network; they are used for increasing the range area of transmitting the wireless data) and end node (dedicated especially for collecting information from the environment). All router nodes have usually the same design, but the end nodes could be dedicated for monitoring different parameters, even they are part of the same network.

In the last year we have worked at the development of a wireless sensors network dedicated for building automation, but which to be used also for other purposes (it is important to have a general design). We are not interested only to measure ambient parameters values, but also to be able to control different external systems, characteristic for an office building (e.g. ventilation, heating, air-conditioning). For being able to control, the network node design should include actuators.

\section{THE EXISTENT NETWORK NODE DESIGNS}

A recent research study has been accomplished, for determining the most important types of network nodes developed until now and to choose from them the most suitable for the development of our wireless sensors network. Each type found has been analyzed from the following points of view: possibility to be used in different types of applications (without or with few modifications to its design), modularity (easy hardware reconfiguration of the node, necessary for different characteristics of the device), cost and size (it is important that the node do not disturb visually or other ways the activities of the people nearby). The life time of the network node, directly related to its power consumption, was not much analyzed in the nodes comparison process, since it is much related to the application type. It is very important that the node to have a general structure, and in this way to ensure the possibility to use it in a variety of situations, without fixed constraints related to the type of sensors, communication with the sensors or other elements attachable to the node (Bujdei et al., 2010).

Most of the network nodes, available on the market today, have been developed mainly for educational purposes (e.g. TI CC2420DB) and doesn't allow an extension of their existent tasks (none or too few inputs or outputs for connecting other dedicated sensors and actuators). They usually are with some test sensors already attached and they don't allow other sensors to be easily connected. The cost of them is high and they don't have a physical small size.

Other types ensure a compact and modular architecture but at a high price (e.g. Tyndal, Mica2Dot, iSense, Libelium WaspMote, Particle zPart, MeshBean, MicroStrain). Since we want the entire solution to be implemented at low cost, to use a high cost network node is not a good starting point.

\section{OUR OWN NETWORK NODE DESIGN}

Since we considered not suitable what we have found for our needs, we have decided, believing in the success of our goal, to design and develop one node by our own, taking in consideration the necessities presented above. The first version of the design for the node supposed to build the node device from the scratch. The complexity of this job is high and in short time it was proved that we don't have sufficient time for this task, as we planned.

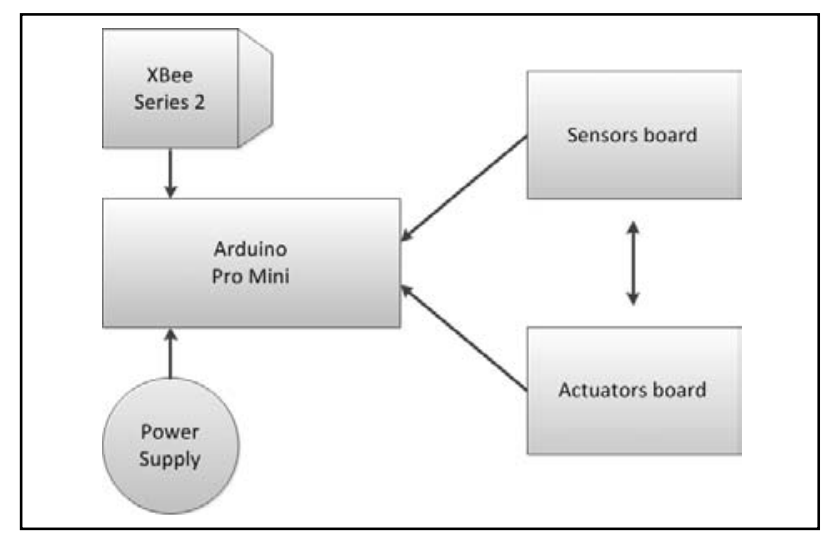

Fig. 1. The main modules of the network node 


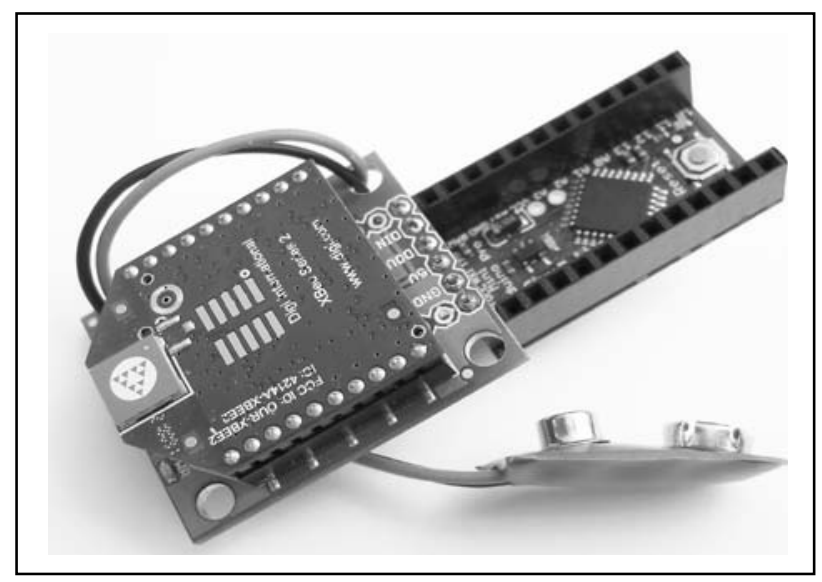

Fig. 2. The end node implementation (only the main modules)

Meantime a new low cost and open source solution has been found: Seeeduino Stalker v2, a development platform created especially for being used for wireless sensors networks. Advantages of it are multiple and it was chosen for our WSN development. The single disadvantages of the platform have been considered to be the non-modular format (many features are not used at each application type) and its physical size.

Since we got meanwhile some experience working with the modules Arduino and XBee, we decided to try in the same time another approach for our node development, based on them (Boonsawat et al., 2010).

A network end node should include some main functional modules: processing unit (micro-processor, analog inputs, digital inputs and outputs), wireless communication unit and power supply (ensure energy to all modules). Auxiliary, other modules could be attached as it is necessary (Bellis et al., 2005).

Our proposed end node design, presented in figure 1 , is based on using an Arduino Pro Mini platform (3.3V/8MHz) as a processing unit and an XBee Series 2 module as communication unit. The power supply would be ensured from a simple 9V battery. The Arduino board has integrated a 3.3V voltage regulator which could provide necessary voltage for the $\mathrm{XBee}$ module. In figure 2 it is presented the implementation of the end node. For connecting the Arduino to XBee module a dedicated adapter has been used. At the Arduino board it has been attached female pin headers which allow the developer to connect other auxiliary boards. For this stage it was planned to be developed and use a sensors board, an actuators board or a mixed board of sensors and actuators. One of the biggest advantage of using Arduino and XBee modules is that they could be easily configured and applications for them could also be easily developed (Faludi, 2010; Varchola et al., 2005).

The XBee module, configured to function as an end node, would enter normally a sleep mode for reducing the energy consumption. It just wakes from time to time to verify if there are network messages dedicated to him and to execute eventually scheduled tasks.

The solution proposed is modular (each module could be easily detached and replaced if it is necessary) and could be implemented at a low cost (about 45\$, for the main components). Also it could be used to any type of applications, even it is necessary to read information from sensors or control any external equipment. The only limitation is imposed by the number of inputs and outputs of the processing board. The size is quite small, comparing to other similar devices, and it could be further minimized.

The first tests made with this design of the end node supposed to attach a sensors board, where it was installed only one light sensor. The measured value of the light intensity was send from the end node to the coordinator node and displayed on a LCD screen. Other tests supposed to attach an actuators board which command a lamp attached to the network node. The command of the lamp, at $230 \mathrm{~V}$ voltage, was simply done using relay components.

\section{FUTURE WORK AT THE PROPOSED DESIGN}

The accomplished tests proved to have an acceptable design solution, with multiple possibilities for future implementing. Even so, some optimizations could be done for improving the whole node's functionality:

- another type of power supply is searched to be found, which to have a smaller size and to ensure in the same time a high energy capacity;

- change the existent adapter or the connection, between the Arduino and XBee, for being able to control also the Sleep pin (available on XBee board and which could allow us to wake up the board only when it is necessary), the CTS (Clear to Send) pin and RTS (Ready to Send) pin. The CTS and RTS signals are used to ensure the serial data flow control between the modules.

- change the Arduino Pro Mini, from the 3.3V version to 5V version. The $5 \mathrm{~V}$ voltage will allow us to control better the actuators (relays) and to connect specific sensors which are not functioning at lower voltage. For the other components which require $3.3 \mathrm{~V}$ a voltage regulator would have to be integrated.

\section{CONCLUSION}

The modular architecture, the general concept, the low cost implementation and the possibility of easy reconfiguration make the presented design of the end node to be a future solution with many usage possibilities. The new versions of the design will come even with more benefits. Any new application type, necessary to be developed using this type of end node, will represent a challenge and a step further in our research.

\section{ACKNOWLEDGEMENTS}

This paper is supported by the Sectoral Operational Programme Human Resources Development (SOP HRD), financed from the European Social Fund and by the Romanian Government under the project number POSDRU/89/1.5/S/59323.

\section{REFERENCES}

Bellis, S. J.; Delaney, K.; O’Flynn, B.; Barton, J.; Razeeb, K.M. \&O’Mathuna C.(2005). Development of field programmable modular wireless sensor network nodes for ambient systems, Computer Communications, Vol. 28, No. 13, August 2005, pp. 1531-1544, ISSN: 0140-3664

Boonsawat, V.; Ekchamanonta, J.; Bumrungkhet, K. \&Kittipiyakul, S. (2010). XBee Wireless Sensor Networks for Temperature Monitoring, Proceedings of the $2^{\text {nd }}$ ECTIConference on Application Research and Development, May 10-12, 2010, Pattaya, Chonburi, Thailand

Bujdei, C.; Moraru, S. A. \&Ungureanu, D. (2010). Designing a layered node architecture to be used in Wireless Sensor Networks, Proceedings of the $16^{\text {th }}$ International Conference The Knowledge-Based Organization, November 25-27, 2010, Sibiu, Romania, ISSN: 1843-6722, pp. 370-375, Nicolae Balcescu Land Forces Academy, Sibiu

Faludi, R. (2010). Building Wireless Sensor Networks with ZigBee, XBee, Arduino and Processing, O’Reilly Media, ISBN: 978-0-596-80773-3, Sebastopol

Varchola M. \& Drutarovsky M. (2007), Zigbee based home automation wireless sensor network, Acta Electronica et Informatica, no. 4, vol. 7, ISSN: 1335-8243 